\title{
Trends in Qualitative Research in Three Major Language Teaching and Learning Journals, 2006-2015
}

\author{
Hiroko Tojo ${ }^{1} \&$ Akiko Takagi $^{2, *}$ \\ ${ }^{1}$ Faculty of Education, Miyazaki University, Miyazaki, Japan \\ ${ }^{2}$ Faculty of Education, Psychology, and Human Studies, Aoyama Gakuin University, Tokyo, Japan \\ *Correspondence: Faculty of Education, Psychology, and Human Studies, Aoyama Gakuin University, Tokyo, Japan. \\ Tel: 81-3-3409-8279. E-mail: atakagi@ephs.aoyama.ac.jp
}

Received: January 11, 2017

Accepted: January 21, 2017 Online Published: January 25, 2017

doi:10.5430/ijelt.v4n1p37

URL: http://dx.doi.org/10.5430/ijelt.v4n1p37

\begin{abstract}
This study examines the current trends and complexities in qualitative research in three major language teaching and learning journals published from 2006-2015. After categorizing 781 articles into quantitative, qualitative, mixed methods, and other approaches, 226 qualitative research articles were closely examined and further analyzed in terms of four dimensions: approaches, methods, number of participants, and length of research period. The findings showed that case study was the most frequently employed approach, followed by ethnography. The study also identified that while interviews, observations, discourse analysis, and conversation analysis were relatively well utilized, more than 150 different data collection and analysis methods were used. Although the results of the study show a tendency to use certain approaches and methods in qualitative research more than others, they also demonstrate the complexity and diversity of qualitative research and the difficulty in clarifying and categorizing types of qualitative research in language teaching and learning.
\end{abstract}

Keywords: qualitative research, approach, method, language teaching and learning

\section{Introduction}

Qualitative research has been widely used in the field of language teaching and learning. Nassaji (2015) holds that the use of qualitative or descriptive research methods has increased to accommodate the complexity of language teaching and learning. Qualitative research enables researchers to examine and understand the complex behaviors and experiences of individual learners. In addition, it is effective for studying classroom teaching since research findings from tightly controlled experimental designs cannot be generalized to other classrooms, each of which have their own contextual differences and complexities.

Although interest in qualitative research has increased, the use of this approach in the field of language teaching and learning is not immediately apparent. There are several potential reasons for this, including the complexity of qualitative methods and the relative newness of using such methods in language teaching and learning research. As Lazaraton (2003) notes, "qualitative research is an umbrella term for a very large group of research methodologies" (p. 3). Qualitative research methodologies that were developed in related disciplines such as anthropology, education, sociology, and psychology have been adapted; therefore, a wide range of qualitative research methodologies is employed in the discipline. A qualitative research methodology is complex because it must consider the approach, epistemology, and data collection and analysis methods. Moreover, adopting qualitative methodologies in language teaching and learning is relatively new-this type of research continues to face criticism in the field, especially as quantitative research remains dominant. Different researchers use different criteria to describe various types of qualitative approaches and methods, and previous research has not clearly revealed which are most effective for research in language teaching and learning.

Although several studies have surveyed the usage trends of qualitative methods for research in language teaching and learning, a complete picture of the approaches and methods employed has not yet been offered. To promote further understanding of the nature of qualitative research as well as the future development of qualitative research in the 
field, this study examines the complexity of qualitative research by investigating the trends of its use. More specifically, this study addresses the following question: What are the trends in the use of qualitative research in the field of language teaching and learning in the last ten years? This study also critically evaluates the current state of qualitative research in the field of language learning and teaching and presents the issues that should be considered in future undertakings of qualitative inquiry.

\section{Literature Review}

\subsection{Previous Research on Trends in Qualitative Research in Language Teaching and Learning}

Quantitative research was the norm before the mid-1990s, but qualitative researchers have been challenging this, and more systematic qualitative research methods have been well received (Benson, 2013). Canagarajah (2016) points out that empirical, experimental, and quantitative research were dominant in the late 1970s and 1980s because TESOL needed to establish itself as a serious discipline by utilizing valued research methods in academia.

Henning (1986) was the first to note the increasing use of qualitative research, reporting the sharp increase in qualitative research articles he found from examining the journals Language Learning $(L L)$ and TESOL Quarterly (TQ) that were published from 1970-1985. Lazaraton (2000) called this period "the first coming of age" (p. 175) of qualitative research. According to Canagarajah (2016), qualitative research conducted in a disciplined and rigorous manner was further supported by $T Q$ 's "Research Guidelines" for quantitative and qualitative research. Beginning in the 2000s, empirical research has been conducted regarding trends in qualitative research in language teaching and learning by analyzing the types of research published in major journals.

For example, Lazaraton (2000) analyzed 332 articles in $L L, T Q$, The Modern Language Journal (MLJ), and Studies in Second Language Acquisition (SSLA) that were published from 1991-1997. She found that only 10\% of the research articles used qualitative methodologies. Most of the qualitative research was published in $T Q$, and more than $90 \%$ of the articles represented quantitative studies published in the other three journals. She further analyzed the methodological approaches of the 33 qualitative research articles. Ethnography was the most frequently employed approach (15 times), followed by analyses of oral and written discourse (11 times). Lazaraton (2005) expanded her initial survey (Lazarton, 2000) to include journals published in 2001 and found that qualitative research articles had increased by $14 \%$, with $40 \%$ of the articles in $T Q$ being qualitative.

Several other studies have supported the trend of increasing qualitative research in language teaching and learning. For example, Gao, Li, and $\mathrm{Lu}(2001)$ analyzed 992 articles published in Applied Linguistics (AL), International Review of Applied Linguistics (IRAL), MLJ, and TQ from 1985-1997. They found that 18\% of the empirical studies were qualitative; further, the number of qualitative research articles has gradually risen each year. In fact, the gap between the number of quantitative and qualitative studies has narrowed since the mid-1990s. This shift was notable in $T Q$, where qualitative studies comprised $47 \%$ of the total and quantitative studies constituted $32 \%$ of the total. The authors also investigated types of qualitative research methods in $T Q$ articles and found that ethnography constituted $32 \%$, text analysis $22 \%$, narrative accounts $17 \%$, verbal reports $25 \%$, and classroom interaction analysis $3 \%$. Text analysis was the dominant method in the other three journals.

Despite selecting different journals, the above three studies demonstrate the general tendency of an increase in qualitative studies in language teaching and learning journals from the 1980s-1990s. However, the results of the studies do not reveal what types of approaches and methods are commonly employed in qualitative research, and they do not make the difference between "approaches" and "methods" clear. Considering this issue, Benson, Chik, Gao, and Wang (2009) extended earlier surveys conducted by various researchers and examined 2,202 qualitative research articles published in 10 major journals (AL, IRAL, LL, MLJ, SSLA, TQ, System, Canadian Modern Language Journal [CMLR], Foreign Language Annals [FLA], and Language Testing [LT]) from 1997-2006. They also conducted a detailed examination to assess patterns in the approaches utilized. Among the 2,202 articles, $22 \%$ (477) were qualitative, including 24 articles that used both qualitative and quantitative methods. The proportion of the total number of qualitative research was higher than that of the three previous studies, but there was no year-to-year increase. The most noticeable result was the variation in the ratios of qualitative research to journals. Among ten articles, the proportion of qualitative articles in three journals ( $A L, C M L R$, and $T Q$ ) was higher than $30 \%$ $(32 \%, 37 \%$, and $43 \%$, respectively), while that of two journals ( $L L$ and $S S L A)$ was less than $10 \%$ (8\% and $5 \%$, respectively).

Among 477 qualitative studies, the authors attempted to clarify the patterns of approaches; however, this was somewhat difficult because approximately $30 \%$ of the articles could be explicitly identified within qualitative 
research traditions. They managed to categorize all of the studies into 16 approaches with regard to comparability. Based on similarities, the authors grouped the approaches together and came up with two broad categories. One category constituted the investigation of the people, situations, and social processes involved in language learning, and the second category comprised investigations of spoken and written texts. The former category included 10 approaches, and the total number of articles belonging to this category was 344 . Out of this total, 225 were case studies, 49 were ethnographic approaches, and 19 were longitudinal studies. The latter category included six approaches, with a total article count of 133, of which 53 employed discourse analysis, 49 utilized classroom interaction, and 20 consisted of conversation analysis. The methods of data collection were further analyzed for the articles in the first category. A total of 103 articles used one type of data collection, 157 used a combination of two or three types, and 71 used more than four types.

Though investigations of methodological trends often focus on prominent journals in the field of language learning and teaching, studies examining lesser-known publications in the field also yield important findings. For example, Kleinsaasser (2013) investigated 79 articles focusing on language teachers, language(s) teacher education, teaching, and learning that were published in Teaching and Teacher Education (TTE) from 1985-2012. The results of the analysis revealed that 59 articles employed a qualitative method, 12 utilized a quantitative method, and eight used both qualitative and quantitative methods. The most prevalent themes in these studies were narrative inquiry and identity. Although TTE cannot be classified as a major journal in the field of language learning and teaching, it is notable that qualitative research is more widely employed than quantitative research and that narrative inquiry is commonly utilized in articles concerning language teachers and language teacher education.

\subsection{Approaches and Methods in Qualitative Research in Language Teaching and Learning}

An examination of studies surveying trends in qualitative research suggests an overall rise in this approach; however, there is still no clear picture of the exact qualitative approaches and methods employed. Although Benson et al. (2009) attempted to distinguish different approaches, it is questionable whether only one approach was used in all of the studies surveyed. Moreover, there is no clear framework that distinguishes the various approaches used in qualitative research.

Benson et al. (2009) stated, "distinct approaches to qualitative research are not easily identified in published work" (p. 83). Some researchers describe their work as qualitative, referring to approaches such as ethnography and narrative inquiry, but others simply use qualitative methods without referring to any approach. Benson (2012) pointed out that quantitative research has dominated applied linguistics, having been introduced in the mid-1990s. Thus, the adoption of qualitative research methodologies is relatively new to applied linguistics compared to other disciplines in the social sciences. Consequently, there is no clear consensus on the criteria for qualitative research methodologies in applied linguistics.

Moreover, in comparison to quantitative research based on a positivist paradigm, qualitative research employs a variety of approaches, allowing investigators to rely on different philosophical assumptions when conducting research. Therefore, simply referring to "methods" such as observations and interviews is not appropriate in studies in order to clarify the philosophical assumption a particular research depends on. In other words, researchers should be keenly aware of the philosophical underpinnings of the qualitative "approaches" they employ. In the context of language teaching and learning research, it is difficult to identify and categorize the approaches used in qualitative studies. For example, one researcher may use an approach established in traditions of qualitative research, such as ethnography, while another researcher may use a case study approach, which can also be employed in quantitative research. Other researchers may not even mention an approach or may use qualitative methods in the pragmatic paradigm.

Despite this variation in research approach, some researchers have asserted their views on which approaches are effective for research in language teaching and learning. Lazaraton (2003) regarded conversational analysis and ethnography as two prevalent approaches in applied linguistics research, whereas Richards (2003) delineated seven core methods: ethnography, grounded theory, phenomenology, case study, life story, action research, and conversational analysis. More recently, Heigman and Crocker (2009) proposed five approaches for language teaching and learning research: narrative inquiry, case study, ethnography, action research, and mixed methods. The 24 approaches presented by Benson et al. (2009) are much broader, including case study, ethnography, think aloud, diary study, discourse analysis, classroom interaction, etc. Although grounded theory and phenomenology are prominent in other social sciences, they do not occupy an important place in language teaching and learning research (Richards, 2009).

Notwithstanding these efforts, previous studies do not clarify and categorize the surveyed approaches and methods 
employed in qualitative research, most likely due to the difficulty involved in distinguishing approaches. Therefore, the picture of the use of qualitative methodology in language teaching and learning research remains incomplete. In addition to issues relating to approaches and methods, few previous studies have closely investigated the detailed aspects of qualitative studies, such as the number of participants and the length of the research period. Thus, this study selected 781 articles from three journals published over the last ten years and examined the complexity of 226 qualitative research studies in greater detail.

The purpose of this research was two-fold. First, it aimed to illustrate qualitative research conducted in three major language teaching and learning journals in the past ten years (2006-2015). Second, it aimed to investigate the complexity of qualitative research by determining patterns in terms of four dimensions: approaches, methods, number of participants, and length of research.

\section{Method}

\subsection{Procedure}

Six procedures were followed. After discussion, it was decided which international journals would be investigated in detail. Of the ten international journals that Benson et al. (2009) investigated, TESOL Quarterly (TQ) (2006-2015), Modern Language Journal (MLJ) (2006-2015), and Applied Linguistics (AL) (2006-2015) were chosen to explore the tendencies and features of qualitative research in language teaching and learning during the past ten years. While $43 \%$ of $T Q$ is qualitative, $32 \%$ of $A L$ and $23 \%$ of $M L J$ are qualitative (Benson et al., 2009). Moreover, $A L$ and $M L J$ both have relatively high impact factors (1.026 and 0.750) in applied linguistics (Egbert, 2007). After deciding to focus on these three journals, 781 articles that appear in the "Article" sections of the three journals for the last ten years were analyzed.

Because $T Q$ has been shown to have "the highest percentage (43\%) as well as the highest overall number of articles" (Benson et al., 2009, p. 83) among the six journals that favor qualitative articles, $T Q$ was selected as the first choice for analysis. All of the articles taken from $T Q$ (2004-2013) were sorted into ten categories, which were later consolidated into four types: qualitative, mixed, quantitative, and others. Then, the articles assigned as qualitative and mixed methods were more closely investigated considering four different dimensions: approaches, methods, number of participants, and length of the research period. Information regarding participant(s) in each article was also examined. When the effectiveness of this process was agreed upon, it was applied to $M L J$ and $A L$. All of the studies under analysis were coded per methodological category multiple times. The overall inter-coder agreement rate was $94 \%$ - any differences were discussed and resolved.

\subsection{Types of Categorization}

$T Q$ (2004-2013) was chosen for a trial to clarify the features of the qualitative approaches and methods in the three journals. By doing so, the possibilities of which methodologies were employed the most in qualitative articles could be estimated. This was necessary in order to determine whether qualitative analyses utilized in mixed methods research are likely to influence the characteristics of qualitative research, or at least to be aware that mixed methods research should be interpreted as a part of qualitative research. Each abstract and methodology was examined to ascertain what types of approaches and methods were employed in each individual article in $T Q$. In cases where the abstract and/or methodology did not reveal the type of approach or method used, the entire paper was read to obtain the information. Ultimately, ten categories were created to differentiate qualitative, mixed method, quantitative, and other approaches (Table 1). 
Table 1. Categories to Differentiate Qualitative, Mixed Method, Quantitative, and Other Approaches

\begin{tabular}{ll}
\hline Approaches & Categories \\
\hline Qualitative & 1. The author(s) explicitly state that the study is qualitative. \\
Qualitative & 2. Although the author(s) do not explicitly say so, the data is analyzed qualitatively. \\
Qualitative & 3. It can be reasonably assumed that the study is qualitative. \\
Mixed methods & 4. The author(s) state that the study uses mixed methods. \\
Mixed methods & $\begin{array}{l}\text { 5. The author(s) do not say that the study is mixed methods; however, it can be interpreted } \\
\text { as a mixed methods study by analyzing it first qualitatively and then quantitatively. }\end{array}$ \\
Mixed methods & $\begin{array}{l}\text { 6. The study can be regarded as a mixed methods study by first analyzing the data } \\
\text { quantitatively and then qualitatively. }\end{array}$ \\
Quantitative & $\begin{array}{l}\text { 7. The author(s) state that the study is quantitative. } \\
\text { Quantitative }\end{array}$ \\
8uantitative & $\begin{array}{l}\text { 9. It can be reasonably assumed that the study is quantitative. } \\
\text { Others }\end{array}$
\end{tabular}

\subsection{Features of Qualitative Research}

Based on the framework in Heigham and Croker (2009), the features of qualitative research were investigated and categorized into five dimensions: approaches (narrative inquiry [NI], case study [CS], ethnography, action research [AR], mixed methods [MM], and others), methods (observation, interviews, open response items in questionnaires [ORIQ]; introspective techniques [IT]; discourse analysis [DA]; conversation analysis [CA]; and others), the number of participants (1 person, 2-5 people, 6-10, 11-20, 21-50, 51-100, more than 100 people, and N/A), and the length of the research period (less than one year, more than one year, and N/A). Heigham and Croker's (2009) framework was chosen because it is a relatively new publication and concerns both approaches and methods that are widely used in language teaching and learning research.

In terms of approaches and methods, Heigham and Croker's (2009) framework was followed; however, some of the definitions were broadened and adjusted. Especially, DA was distinguished from CA because CA is a well-established research method, as can be seen in $T Q$ 's "Research Guidelines" from 2003 (Chapelle \& Duff, 2003). Table 2 shows the definitions used for this report. In cases where two or three methods were used within one study, each method was counted as one. This way of counting multiple methods numerically is used throughout the study.

Table 2. Definitions

\begin{tabular}{ll}
\hline $\begin{array}{l}\text { Approachesand } \\
\text { methods }\end{array}$ & Definitions \\
\hline CS & Written as CS; titles contain + in certain places; findings are focused within some boundary \\
Ethnography & Written as ethnography; wordings such as classroom observation and longitudinal \\
NI & Written as NI; wordings such as narrative(s), life story, and life history \\
AR & Written as AR; wordings such as practitioner(s) \\
Interview & Written as interview(s), including focus group interview(s) \\
DA & Written as DA including critical discourse analysis; writings contain transcribed protocols \\
CA & Written as CA; writings contain transcribed protocols with CA signs \\
ORIQ & Written as open response questionnaire \\
IT & Written as introspective techniques and simulated recall \\
\hline
\end{tabular}


Five categories were created to organize the detailed information describing participants: teacher(s); student(s); teacher(s) and student(s); others, including principal(s), local district administrator(s), and parent(s); and N/A. The procedures were applied for $M L J$ (2006-2015) and $A L$ (2006-2015); the information in $T Q$ (2014-2015) was also added, while information in $T Q$ (2004-2005) was deleted.

\subsection{Differentiating Mixed Methods Research from Qualitative Research}

After conducting the examination procedures for the studies in $T Q$ (2004-2013), it was concluded that there is little possibility that using qualitative analyses in mixed methods research affects how qualitative research takes place. There are two reasons for this. First, per Tojo and Takagi (2014), out of 216 articles in TQ (2004-2013), 84 were qualitative research (39\%), 31 were mixed methods research (14\%), 71 were quantitative research (33\%), and 30 represented other types of research (14\%). Second, while the total number of approaches using qualitative research was 127 , mixed methods research comprised only six case studies, and the other mixed methods studies did not refer to approaches at all. This is not surprising considering that mixed methods research is often employed at the pragmatic level in order to thoroughly investigate research questions by combining quantitative and qualitative methods. Based on these findings, it was judged that six of the reports using case studies did not have a great impact on revealing the complex nature of qualitative research. Thus, in this paper, any aspects of mixed methods research were removed to identify the features of qualitative research. However, it was acknowledged that mixed methods research has recently gained considerable attention in the field, and as Hasemi and Babali (2015) argued, integrating the two methods in a rigorous mixed methods research design will greatly enahance research.

\section{Results}

This section contains the overall methodological tendencies among the three journals as well as some features of the qualitative studies. Table 3 illustrates that 226 qualitative, 100 mixed methods, and 277 quantitative research papers have been published in the three journals for the past ten years.

If qualitative research and mixed methods research are conventionally unified, 326 articles out of the 781 contain qualitative research (42\%), which is somewhat higher than the 33\% that Benson et al. (2009) reported. $T Q$ occupies the highest rate of qualitative research (38\%), whereas $A L$ shows the lowest $(25 \%)$ among the three journals. The number of qualitative research studies in $T Q(85)$ and $A L(63)$ is more than that of quantitative research (79 in $T Q$ and 53 in $A L$ ). In $M L J$, qualitative research (78) appears less often than quantitative research (145).

Table 3. Overall Tendencies of Research Methodologies

\begin{tabular}{|c|c|c|c|c|}
\hline \multirow[b]{3}{*}{ Methodologies } & \multicolumn{4}{|c|}{ Number of articles } \\
\hline & $T Q$ & $A L$ & $M L J$ & Total \\
\hline & $\mathrm{n}(\%)$ & $\mathrm{n}(\%)$ & $\mathrm{n}(\%)$ & $\mathrm{n}(\%)$ \\
\hline QL & $85(38)$ & $63(25)$ & $78(26)$ & $226(29)$ \\
\hline $\mathrm{MM}$ & $31(13)$ & $37(15)$ & $32(11)$ & $100(13)$ \\
\hline QT & $79(34)$ & $53(21)$ & $145(48)$ & $277(35)$ \\
\hline Others & $35(15)$ & $96(39)$ & $47(15)$ & $178(23)$ \\
\hline Total & $230(100)$ & $249(100)$ & $302(100)$ & $781(100)$ \\
\hline
\end{tabular}

Note. $\mathrm{QL}=$ qualitative, $\mathrm{MM}=$ mixed methods, $\mathrm{QT}=$ quantitative

Among the 226 qualitative research studies ( 85 in $T Q, 63$ in $A L$, and 78 in $M L J$ ), 281 qualitative and 536 qualitative methods were found (Table 4). The total number of qualitative methods was almost double the number of approaches, which means that in many cases, a single study employed more than two methods. $A L$, however, was rather exceptional, as most of its publications employed a single qualitative approach. Thus, the procedure of qualitative analysis in $A L$ was more consolidated and often rigorous enough to be considered as a legitimate qualitative study compared to $T Q$ and $M L J$, which often demonstrated more complex, modified, and non-linear processes of qualitative research. 
Table 4. Number of Approaches and Methods in Qualitative Research Studies

\begin{tabular}{lcccc}
\hline & \multicolumn{3}{c}{ Number of articles } & Total \\
\cline { 2 - 5 } & $T Q$ & $A L$ & $9 L J$ & 281 \\
\hline Approaches & 114 & 68 & 228 & 536 \\
Methods & 210 & 98 & 28 & \\
\hline
\end{tabular}

Table 5 shows the types of approaches and methods employed in qualitative research. Of all the qualitative approaches, CS occupied 65\%, followed by ethnography (16\%) and NI (13\%). In contrast to approaches, none of the methods were exclusively outstanding in number. Interview (23\%), observation (16\%), DA (17\%), and CA (9\%) were also commonly employed as applicable methods. There were 159 methods (30\%) in the others category (e.g., survey, students' text analysis, material analysis, sociograms, and think aloud), which may support the notion of qualitative research as being inherently complex.

Table 5. Types of Approaches and Methods in Qualitative Research Studies

\begin{tabular}{clcccc}
\hline & & \multicolumn{4}{c}{ Number of articles } \\
\cline { 3 - 5 } & & $T Q$ & $A L$ & $M L J$ & Total \\
\hline Approaches & $\mathrm{n}(\%)$ & $\mathrm{n}(\%)$ & $\mathrm{n}(\%)$ & $\mathrm{n}(\%)$ \\
& CS & $63(55)$ & $53(79)$ & $65(66)$ & $181(65)$ \\
& Ethnography & $27(24)$ & $5(7)$ & $14(14)$ & $46(16)$ \\
& NI & $17(15)$ & $7(10)$ & $12(12)$ & $36(13)$ \\
& AR & $7(6)$ & $1(1)$ & $7(7)$ & $15(5)$ \\
& Others & $2(3)$ & $1(1)$ & $3(1)$ \\
& Total & $0(0)$ & $68(100)$ & $99(100)$ & $281(100)$ \\
& Interview & $114(100)$ & $24(24)$ & $44(19)$ & $126(23)$ \\
& Observation & $58(28)$ & $9(9)$ & $37(16)$ & $88(16)$ \\
& DA & $42(20)$ & $30(31)$ & $37(16)$ & $90(17)$ \\
& CA & $23(11)$ & $26(27)$ & $17(8)$ & $49(9)$ \\
& IT & $6(3)$ & $0(0)$ & $10(4)$ & $15(3)$ \\
& ORIQ & $5(2)$ & $0(0)$ & $4(2)$ & $9(2)$ \\
& Others & $5(2)$ & $9(9)$ & $79(35)$ & $159(30)$ \\
& Total & $71(34)$ & $98(100)$ & $228(100)$ & $536(100)$ \\
\hline
\end{tabular}

Table 6 describes findings regarding the number of participants and the length of the research period. In terms of the number of participants, almost half of all of the qualitative research articles involved less than ten participants (1 participant, 14\%; 2-5 participants, 25\%; and 6-10 participants, 14\%), which means that most of the qualitative research studies used a relatively small number of participants. Thus, each article may result in a rather small scale of study. As for the length of the research period, longitudinal research was conducted less often than short-term investigations. 
Table 6. Number of Participants and Length of Research Period in Qualitative Research Studies

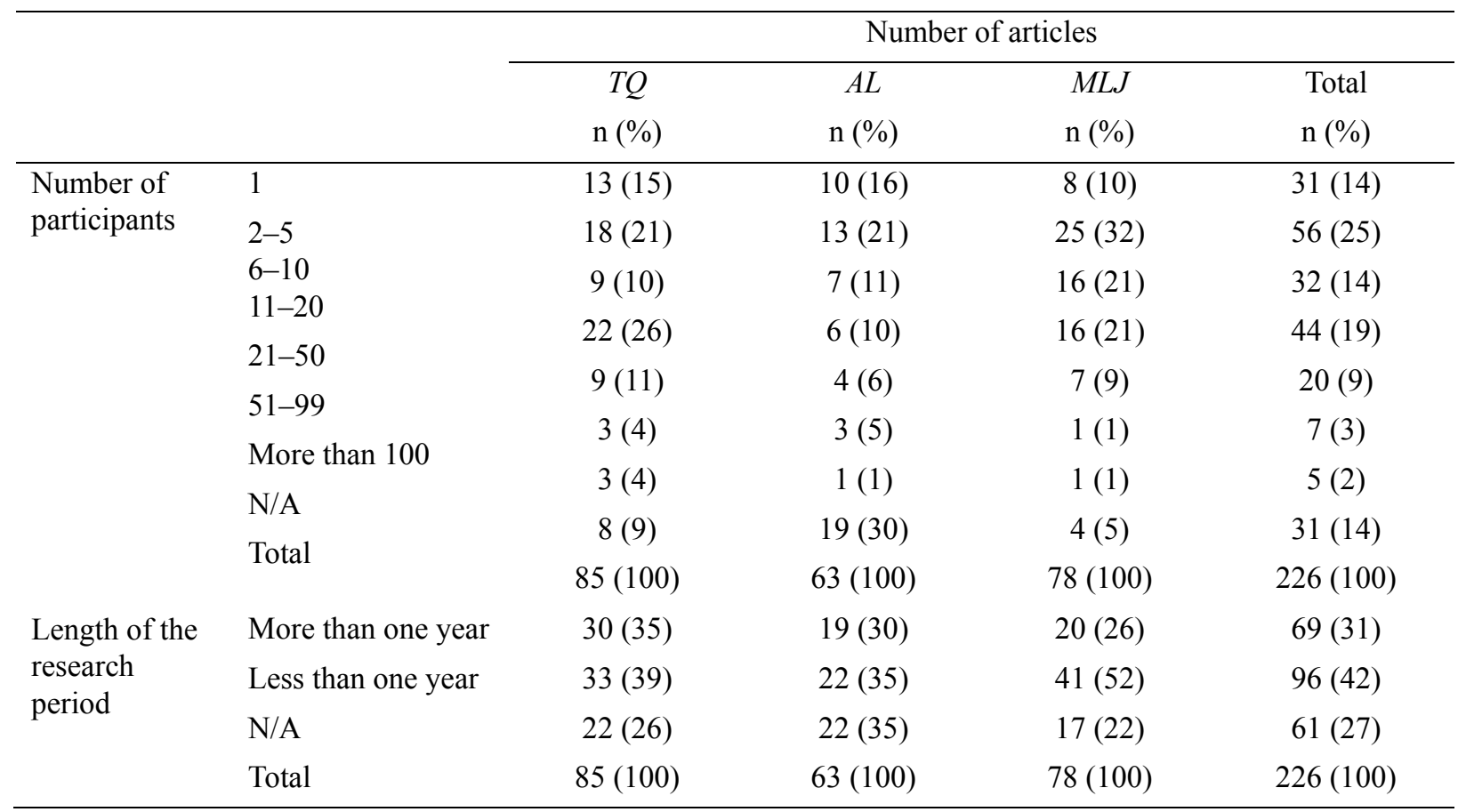

Table 7 shows participant(s)' attribution in qualitative research. Out of 226 qualitative research papers, 191 (79\%) concerned one or both the teacher(s) and learner(s) as participants. In addition, some papers had more than two attributions, pushing the total number to 243. This is not a surprising result, given that qualitative research is often employed when dealing with participants' experiences and perceptions.

Table 7. Participant(s)' Attribution in Qualitative Research Studies

\begin{tabular}{lcccc}
\hline & \multicolumn{4}{c}{ Number of articles } \\
\cline { 2 - 5 } Participant(s)' attribution & $T Q$ & $A L$ & $M L J$ & Total \\
& $\mathrm{n}(\%)$ & $\mathrm{n}(\%)$ & $\mathrm{n}(\%)$ & $\mathrm{n}(\%)$ \\
\hline Teacher(s) & $28(30)$ & $7(10)$ & $19(24)$ & $54(22)$ \\
Learner(s) & $35(37)$ & $32(46)$ & $41(51)$ & $108(44)$ \\
Teacher(s) and learner(s) & $11(12)$ & $7(10)$ & $11(14)$ & $29(12)$ \\
Others & $17(18)$ & $13(19)$ & $9(11)$ & $39(16)$ \\
N/A & $3(3)$ & $10(15)$ & $0(0)$ & $13(5)$ \\
Total & $94(100)$ & $69(100)$ & $80(100)$ & $243(100)$ \\
\hline
\end{tabular}

Finally, Table 8 illustrates the relationship between approaches and methods in qualitative research. One hundred and seventy-six articles utilized one approach, 45 contained two approaches, and five used three approaches. While 75 studies employed one approach and method, some studies utilized three approaches - one study even employed six methods and three approaches simultaneously. This phenomenon indicates how varied qualitative research can be. 
Table 8. The Relationship between Approaches and Methods

\begin{tabular}{lcccccccccccc}
\hline & \multicolumn{1}{c}{ Number of methods } \\
\cline { 2 - 6 } of & 1 & 2 & 3 & 4 & 5 & 6 & 7 & 8 & 9 & N/A & Total \\
approaches & & & & & & & & & & \\
\hline One approach & 75 & 43 & 32 & 12 & 10 & 2 & 0 & 0 & 0 & 2 & 176 \\
Two approaches & 3 & 11 & 15 & 8 & 5 & 1 & 1 & 0 & 1 & 0 & 45 \\
Three approaches & 0 & 1 & 1 & 1 & 1 & 1 & 0 & 0 & 0 & 0 & 5 \\
\hline
\end{tabular}

\section{Discussion}

The results of the study show that 326 out of 781 articles employed qualitative methodology either within qualitative research or mixed methods research $(42 \%)$, which represents a higher rate than was found in previous studies. In addition, 226 articles (29\%) undertook qualitative research. This indicates that more qualitative studies have been conducted in the last decade in the field of language teaching and learning. Of the 226 articles, 176 used one approach, 45 used two approaches, and five used three approaches. This implies that although Benson et al. (2009) delimited strict categorizations of qualitative approaches, studies do not always employ a single qualitative approach to conduct research. Ethnography, narrative inquiry, and case study were the most frequently used approaches. Compared to previous studies, ethnography and case study were the most utilized approaches, but narrative inquiry appeared to have increased in the last decade. TQ's epoch-making "Research Guidelines" (Chapelle \& Duff, 2003) listed "case study research" and "(critical) ethnography" in its section on qualitative research. This may partly explain why the two approaches (case study and ethnography) remained popular in the three journals investigated here. However, it is also true that a certain number of researches dealt with a single participant (14\%), and 75 out of 226 qualitative studies (33\%) employed a single approach and a single method. It is often pointed out that qualitative research is relatively small in scale (Benson, 2013), and the findings of the present study support this view. Small-scale study itself is not problematic because it is crucial to understand the meaning of language learning and its use in context at a deeper level. King and Mackey (2016) suggested that from a layered perspective, which means "thinking seriously about theoretical generalizability" (p. 221), qualitative researchers can contribute more to building cases and offering descriptions that can be easily used for comparisons and meta-analysis among cases.

While ethnography and narrative inquiry have long traditions with established philosophical underpinnings, the case study approach is somewhat problematic because it constitutes a broader category. Case study covers various research underpinnings and several different epistemological assumptions. In fact, many studies utilizing more than two approaches employed case study along with another approach.

Although none of the methods were dominant, interview and observation were the most commonly used probably because these methods enable researchers to obtain rich data. DA and CA were also relatively commonly used. According to an editor of $A L$ who examined major topics coverd in the journal over the years, ariticles focusing on discourse (text) analysis increased from $17 \%$ in the first issues (1980-1984) to $25 \%$ in more recent issues (2009-2013) because of the availability of corpus linguistics tools (Hellermann, 2015). In addition, Benson (2013) pointed out that the use of discourse methods has risen "to investigate processes of language teaching, and use" (pp. 4776-4777). This trend is supported by the fact that TQ's "Reserch Guidelines" in 2003 (Chapelle \& Duff, 2003) and 2016 (Mahboob et al., 2016) include sections on DA and CA.

In terms of classification, it was not difficult to categorize the studies per methodological approach. Even if the authors did not explicitly mention their approach, an approach could be assigned by evaluating the studies' descriptions. However, it was somewhat difficult to categorize methods because while some methods could be classified into either data collection methods or data analysis methods, others were a combination of data collection and analysis methods and could not be clearly separated. As for DA and CA, previous studies regarded them as approaches; however, this study concluded that DA and CA could not be classified as approaches because many studies used them as a method without referring to their epistemological assumptions.

The findings in this study support Benson et al.'s (2009) opinion regarding what constitutes qualitative research. As they maintained, it is problematic to have a strict view of what classifies qualitative research because some studies do not demonstrate a clear, qualitative methodological framework with philosophical assumptions that are established in studies in other social sciences. Rather, this study found a wide variety of qualitative methodologies as well as different interpretations. In other words, some studies employ rigorous qualitative research methodologies, but others 
regard qualitative methodology more loosely. Thus, when looking toward the further development and promotion of qualitative research, various types of qualitative methodologies should be accepted. At the same time, researchers should consider how rigorous qualitative methodologies should be employed in the field of language teaching and learning while being conscious of the discipline's underpinning epistemology.

\section{Conclusion}

The results of the study showed that the number of qualitative research articles in the field of language teaching and learning has increased in the last decade. Although categorizing and clarifying types of approaches and methods was not a simple process, the findings demonstrated general trends in recent qualitative research as well as the complex and diverse nature of qualitative research in language teaching and learning. Also, the results of the study revealed the complex nature of qualitative research utilized in language teaching and learning to some extent, which previous research has not dealt with, by investigating details such as the number of participants and the length of the research period.

One of the limitations of this research was that it only examined three journals. Analyzing a wider range of journals may provide a clearer picture of qualitative research in language teaching and learning. Another limitation is that research purposes and research questions were not closely examined. Investigating the relationship between research purposes and types of approaches may reveal them most appropriate approaches to investigate a topic and present practical implications for future research. Finally, further investigation is needed regarding how qualitative methods are utilized in mixed methods research. Although mixed methods research has attracted attention in the social sciences, theoretical aspects of highly qualified mixed methods research have not yet been discussed or fully understood in language teaching and learning research (Hashemi, 2012). By examining the role of qualitative methods in mixed methods research, a more comprehensive understanding of research methodologies that are suitable for language teaching and learning research can be obtained. Moreover, more rigorous research methodologies for studying language teaching and learning can be developed. Such methodologies consider the paradigms underpinning qualitative and mixed methods research. It should be noted that rather than arguing methodologies only in terms of quantitative versus qualitative research paradigms, we need to push the boundaries of methodologies and incorporate a variety of perspectives in collaboration with researchers trained in different disciplines (King \& Mackey, 2016).

\section{References}

Benson, P. (2013). Qualitative methods: Overview. In C. A. Chapelle (Ed.), The encyclopedia of applied linguistics (pp. 4773-4783). Oxford: Wiley-Blackwell.

Benson, P., Chik, A., Gao, X., Huang, J., \& Wang, W. (2009). Qualitative research in language teaching and learning journals, 1997-2006. The Modern Language Journal, 93(1), 79-90. http://dx.doi.org/10.1111/j.1540-4781.2009.00829.x

Canagarajah, S. (2016). TESOL as a professional community: A half-century of pedagogy, research, and theory. TESOL Quarterly, 50(1), 156-178. http://dx.doi.org/10.1002/tesq.275

Chapelle, C. A., \& Duff, P. A. (2003). Some guidelines for conducting quantitative and qualitative research in TESOL. TESOL Quarterly, 37, 156-178. http://dx.doi.org/10.2307/3588471

Egbert, J. (2007). Quality analysis of journals in TESOL and applied linguistics. TESOL Quarterly, 41(1), 157-171. http://dx.doi.org/10.1002/j.1545-7249.2007.tb00044.x

Gao, Y., Li, L., \& Lu, J. (2001). Trends in research methods in applied linguistics: China and the West. English for Specific Purposes, 20, 1-14. http://dx.doi.org/10.1016/S0889-4906(99)00015-0

Hashemi, M. R. (2012). Reflections on mixing methods in applied linguistics research. Applied Linguistics, 33(2), 206-212. http://dx.doi.org/10.1093/applin/ams008

Hashemi, M. R., \& Babaii, E. (2013). Mixed methods research: Toward new research designs in applied linguistics. The Modern Language Journal, 97(4), 828-852. http://dx.doi.org/10.1111/j.1540-4781.2013.12049.x

Heigham, J., \& Crocker, A. R. (Eds.). (2009). Qualitative research in applied linguistics: A practical introduction. New York: Palgrave Macmillan.

Hellermann, J. (2015). Three contexts for my work as co-editor: Introduction to the special issue. Applied Linguistics, 
36(4), 419-424. http://dx.doi.org/10.1093/applin/amv043

Henning, G. (1986). Quantitative methods in language acquisition research. TESOL Quarterly, 20(4), 701-708. http://dx.doi.org/10.2307/3586520

King, K. A., \& Mackey, A. (2016). Research methodology in second language studies: Trends, concerns, and new directions. The Modern Language Journal, 100 (Supplement 2016), 209-227. http://dx.doi.org/10.1111/modl. 12309

Kleinsasser, R. C. (2013). Language teachers: Research and studies in language(s) education, teaching, and learning in teaching and teacher education, 1985-2012. Teaching and Teacher Education, 29, 86-96. http://dx.doi.org/10.1016/j.tate.2012.08.011

Lazaraton, A. (2000). Current trends in research methodology and statistics in applied linguistics. TESOL Quarterly, 34(1), 175-181. http://dx.doi.org/10.2307/3588103

Lazaraton, A. (2003). Evaluative criteria for qualitative research in applied linguistics: Whose criteria and whose research? The Modern Language Journal, 87(1), 1-12. http://dx.doi.org/10.1111/1540-4781.00175

Lazaraton, A. (2005). Qualitative research methods. In E. Hinkel (Ed.), Handbook of research in second language learning (pp. 209-224). Mahwah, NJ: Erlbaum.

Mahboob, A., Paltridge, B., Phakiti, A., Wagner, E., Starfield, S., Burns, A., . . . De Costa, P. I. (2016). TESOL Quarterly research guidelines. TESOL Quarterly, 50(1), 42-65. http://dx.doi.org/10.1002/tesq.288

Nassaji, H. (2015). Qualitative and descriptive research: Data types versus data analysis. Language Teaching Research, 19(2), 129-132. http://dx.doi.org/10.1177/1362168815572747

Richards, K. (2003). Qualitative inquiry in TESOL. Basuingstoke, England: Palgrave Macmillan.

Richards, K. (2009). Trends in qualitative research in language teaching since 2000. Language Teaching, 42(2), 147-180. http://dx.doi.org/10.1017/S0261444808005612

Tojo, H., \& Takagi, A. (2014, August). Shitsuteki-kenkyu oyobi kongo-kenkyu no doko to keiko [Trends and tendencies in qualitative research and mixed method research]. Paper presented at the 40th Conference of Japan Society of English Language Education. Tokushima City, Tokushima, Japan. 